\title{
Synthesis and Study of New Derivatives of Diphenylcarbazide on the Base of $N_{1}$, $N_{1}$-Dioctoxymethylchlorazone Ether
}

\author{
Hajiyeva SR ${ }^{1}$, Shamilov NT1, Bayramov GI1, Huseynov FE1, \\ Aliyeva TI ${ }^{*}$, Rafiyeva HL ${ }^{1}$, Jafarova $\mathrm{NM}^{1}$ and Gullarli GH${ }^{2}$ \\ ${ }^{1}$ Department of Ecological chemistry, Baku State University, Azerbaijan \\ ${ }^{2}$ Azerbaijan Military Academy named after Haydar Aliyev, Azerbaijan
}

*Corresponding author: Aliyeva Tarana Ibragim, Candidate of Chemical Sciences,

\section{Review article \\ Volume 4 Issue 1}

Received Date: December 04, 2019

Published Date: January 07, 2020

DOI: $10.23880 /$ jenr-16000183 and teacher of "Ecological chemistry" department, Baku State University, Azerbaijan, Tel: (+994) 709701452; Email: tarana_chem@mail.ru

\section{Abstract}

A new derivative of diphenylcarbazide was synthesized on the base of chlorazone ether containing 2 units $-\mathrm{CH}_{2} \mathrm{OC}_{8} \mathrm{H}_{17}$ group and 1 ozone group. During application of for the first time synthesised by us $\mathrm{N}_{1}-\left(\mathrm{N}_{1}, \mathrm{~N}_{1}{ }^{\prime}\right.$-dioxtoxymethyl)azone- $\mathrm{N}_{2}$ $\left(\mathrm{N}_{1}{ }^{\prime}, \mathrm{N}_{1}{ }^{\prime}\right.$-dioctoxymethyl)azone- $\mathrm{N}_{4}-\left(\mathrm{N}_{1}{ }^{\prime}, \mathrm{N}_{1}{ }^{\prime}\right.$-dioctoxymethyl)azone- $\mathrm{N}_{5}-\left(\mathrm{N}_{1}{ }^{\prime}, \mathrm{N}_{1}{ }^{\prime}\right.$-dioctoxymethyl)azone diphenylcarbazide (compound B-1) as an anti-corrosion inhibitor has been found that an ecological inhibitory efficiency of this compound in the most aggressive laboratory environment is $99.96-100 \%$, even with density of $0.5,1.0,1.5$. It is scientifically proven that the new diphenylcarbazide derivative (conventionally designated as B-1) is of great environmental and economic importance when used in corrosion protection of steel processing equipment operated in very aggressive environments in the oil-gas and petrochemical industries. The synthesized B-1 is an inhibitory substance that is highly responsive to the current ecological safety requirements.

Keywords: Octoximethyl Group; Chlorazone; Chlorazone Ether; Dioctoxymethyl Chlorazone; Corrosion; Aggressive Environment; Inhibitor; Environmental Effect; Steel Technological Equipment

\section{Introduction}

As it is known, one of the main causes of environmental problems at the end of unforeseen accidents during technological processes in the oil and gas and petrochemical industries are corrosion of steel process equipment. Therefore, as in other industries, one of the main methods of corrosion protection of steel technological equipment in the oil and gas and petrochemical industries is the use of ecologically effective inhibitors. Synthesis and research of new nitrogen-containing organic compounds that meet all the requirements of ecological safety and which are low-cost 
in the field of organic and petrochemical synthesis are considered as one of the topical issues of the era.

In this regard, as noted in the literature [1], organic compounds containing high quantity of nitrogen atoms possess effective inhibitory properties. Based on the results of our studies [2-4], it has been proved that in fact, various functional groups and organic compounds with high nitrogen atoms have an anti-corrosive effect.

$\mathrm{C}_{8} \mathrm{H}_{17} \mathrm{OCH}_{2} \mathrm{Cl} \quad\left(\alpha\right.$-chloroctoxymethyl) and $\mathrm{N}_{1}{ }^{\prime} \mathrm{N}_{1}$ dioctoxymethyl chlorazone ethers [2-3] for the synthesis of the new derivative of diphenylcarbazide (compound B1) were obtained according the methods described in literature. The composition and structure of these ethers were determined by known methods. The results obtained are in line with the indicators given in the literature [2-3]. In view of the foregoing, we have synthesized a new derivative of diphenylkarbazide $\mathrm{B}-1$, based on the chlorazone ether of the two $-\mathrm{CH}_{2} \mathrm{OC}_{8} \mathrm{H}_{17}$ group. Carrying out the reaction of diphenylcarbazide with $\mathrm{N}_{1} \mathrm{~N}_{1}$-dioctoxymethylchlororazone ether according to the procedure described in the literature [2-3], a new, unknown in the literature diphenylcarbazide derivative $\mathrm{N}_{1}-\left(\mathrm{N}_{1}{ }^{\prime} \mathrm{N}_{1}\right.$ '-dioctoxymethyl) azone- $\mathrm{N}_{2}-\left(\mathrm{N}_{1}{ }^{\prime} \mathrm{N}_{1}{ }^{\prime}-\right.$ dioctoxymethyl)azone- $\mathrm{N}_{4}-\left(\mathrm{N}_{1}{ }^{`} \mathrm{~N}_{1}{ }^{`}\right.$-dioctoxymethyl)azone$\mathrm{N}_{5}\left(\mathrm{~N}_{1}{ }^{\prime} \mathrm{N}_{1}\right.$ 'dioctoxymethyl)azone)diphenylcarbazide, compound B-1 (Figure 1).
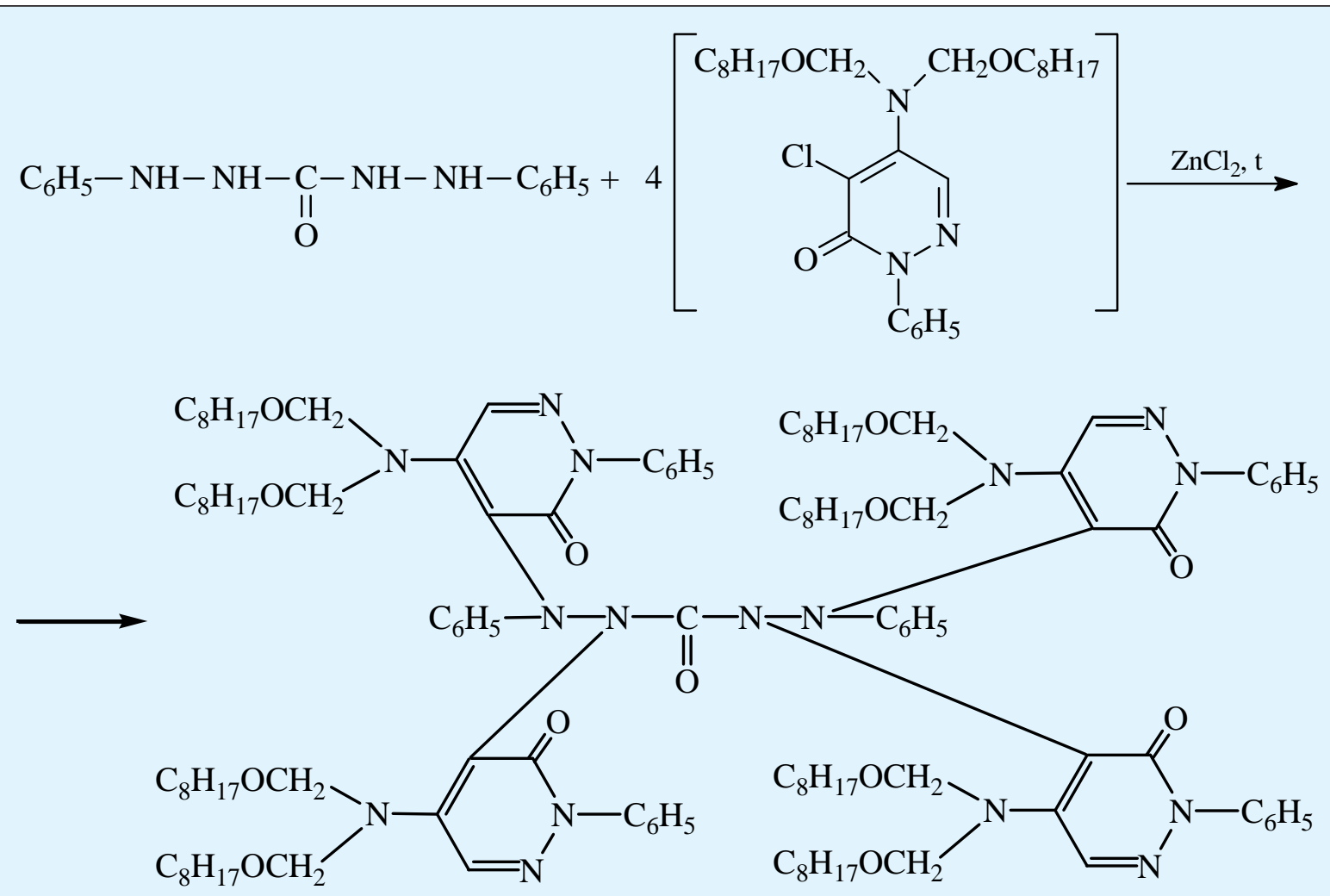

Figure 1: B-1.

The output of the synthesized new B-1 compound of the diphenylcarbazide, its the physical and chemical constants, and the element analyzes are given in Table 1.

Research has been carried out to determine the corrosion rate and inhibitory efficacy of this compound in a highly aggressive environment. According to the study, the inhibitory effect of this compound at the lowest 0.5, $1.0,1.5 \mathrm{mg} / \mathrm{l}$ density was $99.96-100 \%$. Determining the inhibitory efficiency of the new derivative of the synthesized diphenylcarbazide (compound B-1) has been investigated in accordance with method specified in "gravimetric". 


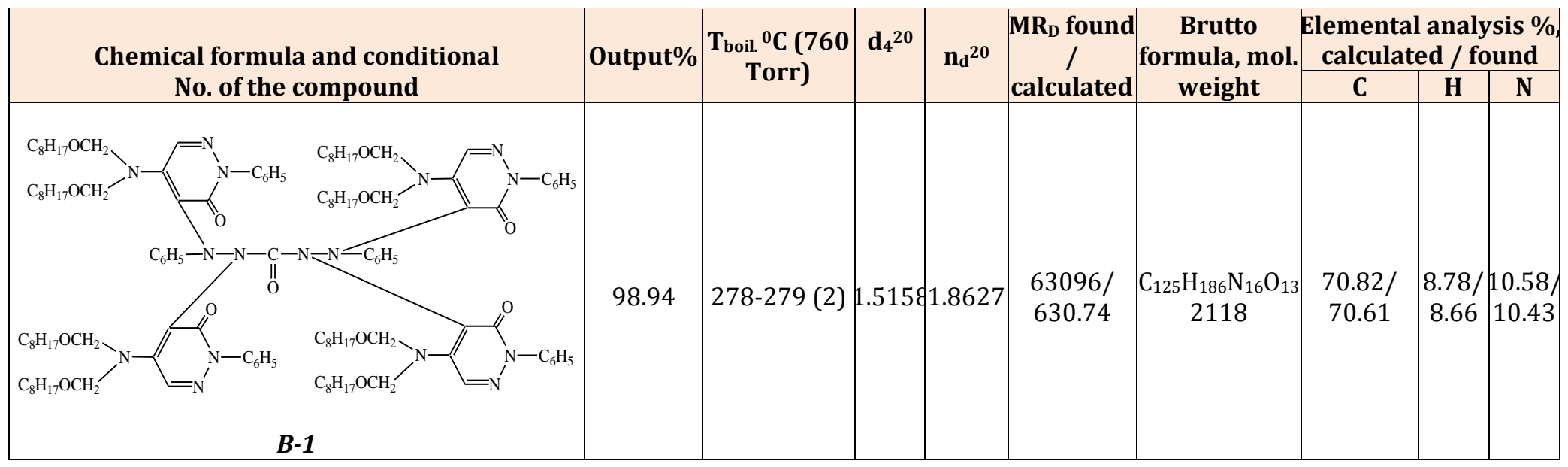

Table 1: Data on the composite output, physical and chemical constants, elemental analysis of the synthesizedN1(N1`N1`dioctoxymethyl)azoneN2(N1`N1`dioctoxymethyl)azoneN4(N1`N1`dioctoximethyl)azone-N5(N1`N1`-dioctoximethyl)azonediphenylcarbazide compound (B-1).

The ecological efficiency of the inhibitory property of the new derivative of diphenylcarbazide - compound B-1, can be explained as follows. Based on the results of our previous studies [2-4] and also the research data in the literature [1,5-12] it can be noted that with the formation of 16 nitrogen atoms in the new diphenylcarbazide derivative, $8 \mathrm{CH}_{2} \mathrm{OC}_{8} \mathrm{H}_{17}$ groups, 31 double bond set, the metal surface becomes passive due to an increase in the influence of electron density and the internal Van der
Waals forces of the compound. As a result, the compound B-1 even at low densities completely reduces the corrosion rate of the metal in the most aggressive environments. Thus, the new derivative B-1 of diphenylcarbazide, shown in Table 2, can be used as an ecologically and economically important inhibitor of corrosion protection of steel technological equipment operated in the most aggressive environments in the oil and gas and petrochemical industries.

\begin{tabular}{|c|c|c|c|c|c|}
\hline \multirow[b]{2}{*}{$\begin{array}{c}\text { conditional } \\
\text { No. of the compound }\end{array}$} & \multirow[b]{2}{*}{$\begin{array}{c}\text { Inhibitor } \\
\text { density, mg/l }\end{array}$} & \multicolumn{2}{|c|}{$3 \% \mathrm{NaCl}(10: 1)+\mathrm{H}_{2} \mathrm{~S} 500 \mathrm{mg} / \mathrm{l}$} & \multicolumn{2}{|c|}{$0.3 \mathrm{~N} \mathrm{HCl}+$ benzine $(1: 7)+\mathrm{H}_{2} \mathrm{~S} 1000 \mathrm{mg} / \mathrm{l}$} \\
\hline & & $\begin{array}{c}\text { Corrosion rate } \mathrm{g} / \mathrm{cm} \\
\text { hour }\end{array}$ & $\begin{array}{c}\text { Inhibitor } \\
\text { efficiency, \% }\end{array}$ & $\begin{array}{l}\text { Corrosion rate, } \\
\text { g/cm hour }\end{array}$ & $\begin{array}{c}\text { Inhibitor } \\
\text { efficiency, \% }\end{array}$ \\
\hline Without Inhibitors & - & 2.56 & - & 3.65 & - \\
\hline \multirow[t]{3}{*}{ 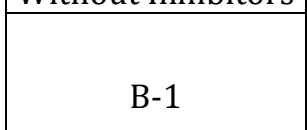 } & 0.5 & 0.0003 & 99.96 & 0.0002 & 99.99 \\
\hline & 1.0 & 0.0002 & 99.99 & 0.0001 & 100 \\
\hline & 1.5 & 0.0001 & 100 & - & - \\
\hline $\mathrm{A}[4]$ & 200 & 0.038 & 98.5 & 0.078 & 98 \\
\hline
\end{tabular}

Table 2: Results of the study of the inhibitory efficiency of a new derivative of diphenylcarbazid (B-1) based on N1 'N1'dioctoxymethylchlorazone ether.

\section{Conclusion}

Synthesis of N1-(N1'N1'-dioctoxymethyl)azone-N2(N1'N1'-dioctoxymethyl) dioctoxymethyl)azon-N5-(N1'N1'dioctoxymethyl)azonedi-phenylcarbazide compound (B-1)

The synthesis tube is filled with $2 \mathrm{~g} \mathrm{ZnCl}_{2}$ catalyst and $0.01 \mathrm{~g} / \mathrm{mol}$ diphenylcarbazide, and $50 \mathrm{ml}$ of $\mathrm{C}_{2} \mathrm{H}_{5} \mathrm{OH}$ alcohol is added and at $70^{\circ} \mathrm{C}$ is mixed until complete dissolution of diphenylcarbazide. Then, $0.04 \mathrm{~g}$-mol $\mathrm{N}_{1}{ }^{\prime}, \mathrm{N}_{1}{ }^{\prime}$ -diocoxymethylchlorazone ether was added to the mixture from a dropping funnel at regular intervals and stirred for 6 hours at $76^{\circ} \mathrm{C}$. After the reaction is complete, $100 \mathrm{ml}$ of $10 \% \mathrm{NaOH}$ solution and $100 \mathrm{ml}$ of distilled water are added to the mixture. Then, $25 \mathrm{ml}$ of diethyl ether is added to the reaction mixture and mixed. The mixture is filled into a separation funnel, and after the organic layer is separated from the water layer, diethyl ether in the organic layer is distilled off by a water pump. 
After being deposited on $\mathrm{CaCl}_{2}$, an organic layer is pumped into vacuum. The composition and structure of the new derivative of diphenylcarbazide (compound B-1) on the basis of $\mathrm{N}_{1}{ }^{\prime} \mathrm{N}_{1}$-dioctoxymethyl chlorazone ether was determined by IR and magnetic mass spectra [13].

In the IR spectrum of the synthesized $\mathrm{N}_{1}-\left(\mathrm{N}_{1}{ }^{\prime} \mathrm{N}_{1}\right.$ dioxtoxymethyl)azone- $\mathrm{N}_{2}-\left(\mathrm{N}_{1}{ }^{`} \mathrm{~N}_{1}{ }^{\prime}\right.$-dioctoxymethyl)azone$\mathrm{N}_{4}-\left(\mathrm{N}_{1} \backslash \mathrm{N}_{1}{ }^{\prime}\right.$-dioctoxymethyl)azone- $\mathrm{N}_{5}-\left(\mathrm{N}_{1} \backslash \mathrm{N}_{1}{ }^{\prime}-\right.$

dioctoxymethyl)azonediphenylcarbazide (B-1) compound there are -C-O-C- simple ether group 1050, $1080 \mathrm{~cm}^{-1} ; \mathrm{CH}_{2}$ group $2950 \mathrm{~cm}^{-1} ; \mathrm{CH}_{3}$ group 1380, 1460, 2960, $3030 \mathrm{~cm}^{-1}$; C-N bond 1310-1350 $\mathrm{cm}^{-1}$; N-N group 900, $1580 \mathrm{~cm}^{-1} ; \mathrm{C}=\mathrm{C}$ bond $1680 \mathrm{~cm}-1$ in the azone group; $\mathrm{C}=\mathrm{C}$ bonds 1440 , $1465,1500,1510,1590-1600 \mathrm{~cm}^{-1}$ in benzene nuclei; $\mathrm{C}_{6} \mathrm{H}_{5}$ group $700-780 \mathrm{~cm}^{-1}$.

The molecular mass of that compound in the magnetic mass spectrum corresponds to the molecular ion of 2118 m/e.

\section{Summary}

For the first time we synthesized a new diphenylcarbazide derivative N1-(N1'N1`dioctoxymethyl) azone N2(N1`N1`dioctoxymethyl)azoneN4(N1`N1`dioctoxymeth yl)azoneN5(N1`N1'dioctoxymethyl)azonediphenylcarbazi de com-pound B-1. The inhibitory effect of this compound in the most aggressive environment in the laboratory conditions was determined. The effectiveness of this compound was $99.96-100 \%$, even at the lowest densities of $0.5,1.0,1.5 \mathrm{mg} / \mathrm{l}$. One can assume that this new diphenylcarbazide derivative by $100 \%$ protects steel processing equipment in the most aggressive environments in the oil and gas and petrochemical industries, and it is important to ensure economic and environmental safety. $100 \%$ corrosion protection and great economic and environmental importance can be considered scientifically sound.

\section{References}

1. Rachev H, Stefanova S (1982) Handbook of corrosion.

2. Bayramov GI (2009) Synthesis and investigation of newly proposed guanidine on the base of khloralkyl and alkenyl-oxymethyl ethers and chlorazone. J Natural and technical Guide 2: 37-43.

3. Gadzhiyeva SR, Bayramov GI, Aliyeva TI, et al. (2019) Synthesis and utilization of novel sulfateimethylene sulfide-based dioxymethylchlorazone ether as an ecologically effective inhibitor. Int Sci J 6: 1-5.

4. Shikhmamedbekova AZ, Mamedyarova IF, Bayramov GI, Mamedaliyeva GG (1983) N, N '- biphenyl - N' octoxytmetyl-guanidine as the corrosion inhibitor of steel in two-phase system. Copyright certificate. USSR, No. 1031141, 1983, A C07 C129 / 12; P23 F $11 / 14$ (in Russian).

5. Shel NV, Tsygankova LE (2007) Novelty inhibitors of corrosion of metals for oil and petrochemical products. Mendeleev's Session on Chemistry and Applied Chemistry: 608.

6. Faritov AT, Khudyakova LP (2003) Methodology for the selection of corrosion inhibitors for OAO Orenburgneft // Problems of the collection, preparation and transport of oil and oil products pp: 167-171.

7. Shirayeva RN, Kudasheva FH, Gumayev N (2009) Inhibition of resin deposits of asphaltenes and paraffins in oil pipelines with chemical reagents. J Chemistry and technology of fuels and oils. M.: Publishing House of the Russian State University of Oil and Gas named after I.M. Gubkin 3: 52-53.

8. Khudyakova LP (2008) A system for ensuring the safe operation of oil and gas equipment and pipelines operating in an aggressive manner: 39 .

9. Investigation of the effect of hydrogen sulfide on corrosion processes in the operational characteristics of structural elements of pipelines and tanks. Problems of the collection, preparation and transport of oil and oil products: Sat. Scientific Engineering, IPTER-2005, 65: 27-40.

10. Khudyakova LP, Spashenko AY, Antipov Yu (2007) Assessment of the degree of danger of stresscorrosion cracks // STJ "Problems, collection, preparation and transport of oil and oil products", IPTER. 3(69): 39-41.

11. Khudyakova LP, Spashenko A, Yu (2007) Estimated rate of corrosion-mechanical cracking of oil and gas equipment and pipelines.// STJ "Problems, collection, preparation and transport of oil and oil products" / IPTER.Ufa. 3(69): 61-63. 
12. Gurvich LM, Sherstiyev NM (1994) Multifunctional surfactant compositions for oil production technological operations. VNIIOENG: 268.

13. Frolova LV, Agafankin FV (2010) Inhibition of hydrogen sulfide corrosion of carbon steels by $\mathrm{N}$ - ethanolbutylene amine and its mixtures with tertiary amine. J corrosion: materials, protection. M.: publ. of LLC "Science and Technology" 1: 15. 